\title{
Environmental influences on maize-Aspergillus flavus interactions and aflatoxin production
}

\author{
Jake C. Fountain ${ }^{1}$, Brian T. Scully ${ }^{2}$, Xinzhi $\mathrm{Ni}^{3}{ }^{,}$Robert C. Kemerait ${ }^{1}$, Robert D. Lee ${ }^{4}$, Zhi-Yuan Chen $^{5}$, \\ and Baozhu Guo ${ }^{1,2}$ *
}

${ }^{1}$ Department of Plant Pathology, University of Georgia, Tifton, GA, USA

${ }^{2}$ Crop Protection and Management Research Unit, Agricultural Research Service - United States Department of Agriculture, Tifton, GA, USA

${ }^{3}$ Crop Genetics and Breeding Research Unit, Agricultural Research Service - United States Department of Agriculture, Tifton, GA, USA

${ }^{4}$ Department of Crop and Soil Sciences, University of Georgia, Tifton, GA, USA

${ }^{5}$ Department of Plant Pathology and Crop Physiology, Louisiana State University, Baton Rouge, LA, USA

\section{Edited by:}

Perng-Kuang Chang, Southern

Regional Research Center, USA

\section{Reviewed by:}

Chuck Niblett, Venganza, Inc., USA Ahmad Fakhoury, Southern Illinois University Carbondale, USA

\section{${ }^{*}$ Correspondence:}

Baozhu Guo, Research Plant Pathologist, Crop Protection and Management Research Unit,

Agricultural Research Service - United States Department of Agriculture, 2747 Davis Road, Tifton, GA 31793, USA

e-mail: baozhu.guo@ars.usda.gov
Since the early 1960s, the fungal pathogen Aspergillus flavus (Link ex Fr.) has been the focus of intensive research due to the production of carcinogenic and highly toxic secondary metabolites collectively known as aflatoxins following pre-harvest colonization of crops. Given this recurrent problem and the occurrence of a severe aflatoxin outbreak in maize (Zea mays L.), particularly in the Southeast U.S. in the 1977 growing season, a significant research effort has been put forth to determine the nature of the interaction occurring between aflatoxin production, $A$. flavus, environment and its various hosts before harvest. Many studies have investigated this interaction at the genetic, transcript, and protein levels, and in terms of fungal biology at either pre- or post-harvest time points. Later experiments have indicated that the interaction and overall resistance phenotype of the host is a quantitative trait with a relatively low heritability. In addition, a high degree of environmental interaction has been noted, particularly with sources of abiotic stress for either the host or the fungus such as drought or heat stresses. Here, we review the history of research into this complex interaction and propose future directions for elucidating the relationship between resistance and susceptibility to $A$. flavus colonization, abiotic stress, and its relationship to oxidative stress in which aflatoxin production may function as a form of antioxidant protection to the producing fungus.

Keywords: maize, aflatoxin contamination, environment effects, oxidative stress, host resistance

\section{INTRODUCTION}

Aspergillus flavus (Link ex Fr.; Teleomorph: Petromyces flavus; Horn et al., 2009a,b) is a facultative, plant parasitic pathogen, which has the ability to colonize a number of common crop species including corn, cotton, peanuts, and many other crops (Diener et al., 1987). Economic losses due to the infection of grain crops such as maize (Zea mays L.) by A. flavus is not primarily due to the expression of symptoms known as Aspergillus ear rot but, rather, is due to the subsequent contamination of the grain with the fungal metabolite aflatoxin. Aflatoxins are a group of polyketide-derived furanocoumarin secondary metabolites produced by certain species of fungi, including the genus Aspergillus (Bennett and Klich, 2003; Chanda et al., 2009). Aflatoxins are highly carcinogenic and can be acutely toxic or fatal if ingested in sufficient quantities for both livestock and humans (Shephard, 2008).

Although this species was first described by Link in 1809 (Amaike and Keller, 2011), major research on the biology and pathogenicity of A. flavus did not commence until the mid 1960s with the incidence of Turkey X disease which killed over 100,000 turkey poults due to aflatoxin contaminated feed associated with A. flavus infected peanuts (Wogan, 1966). Shortly thereafter broad screening of feed and food was initiated, the chemical structures of the major aflatoxins (B1, B2, G1, and G2) were elucidated, and research was conducted to prevent post-harvest contamination of grain crops through the modulation of storage conditions (Asao et al., 1965; Trenk and Hartman, 1970). However, it was found during a particularly severe outbreak of aflatoxin contamination in maize in the late 1970s in the U.S. that it was possible for $A$. flavus to both colonize and produce aflatoxin on developing maize kernels prior to harvest (Diener et al., 1983, 1987).

Since the extensive losses from the 1977 growing season due to aflatoxin contamination (Diener et al., 1983), research efforts have focused on determining the source of host plant resistance to prevent $A$. flavus colonization and subsequent aflatoxin production pre-harvest and before transportation to storage. These efforts have employed numerous techniques and approaches including modern plant breeding and genetics tools such as proteomic, transcriptomic, and biochemical analyses in an effort to discover the underlying mechanism of host plant resistance and the interaction between the two organisms. To date, these efforts have revealed that resistance is quantitatively inherited with a strong genotype by environment component. It is a complex interaction with a high degree of environmentally induced variability with abiotic and biotic stress strongly influencing resistance or susceptibility. Here we review the results of research into the 
mechanism of host resistance to both A. flavus colonization and abiotic stress, and propose future research directions for determining the relationship between oxidative stress and aflatoxin contamination.

\section{HOST RESISTANCE AGAINST A. flavus: GENE-FOR-GENE VS. GENOTYPE $\times$ ENVIRONMENT INTERACTION?}

From a gene-for-gene perspective, host resistance against $A$. flavus colonization and subsequent aflatoxin contamination has been approached as a single virulence factor produced by the invading pathogen that would be countered by a single avirulence or resistance protein in the host. This results in compatible or incompatible reactions based on specific recognition (Keen, 1990). The particular virulence mechanisms of these plant-microbe interactions are utilized to classify plant pathogens into groups such as biotrophic, necrotrophic, and hemibiotrophic pathogens (Glazebrook, 2005).

The classification of $A$. flavus into a particular class of plant pathogens has yet to be determined. A microscopy study of the growth of A. flavus in maize kernel tissue by Smart et al. (1990) showed that cellular components such as cell walls were broken down in advance of mycelia. This has been interpreted as being indicative of necrotrophic pathogenicity in the literature (Mideros et al., 2009), however, not all research concurs with this conclusion. Magbanua et al. (2007) found that the colonization of kernel tissue from resistant maize lines exhibited increased levels of salicylic acid (SA) and unchanged levels of jasmonic acid (JA). Such patterns are commonly associated with resistance to biotrophic pathogens in various plant species (Glazebrook, 2005). As a facultative parasite, which naturally exists as a saprophyte, A. flavus may possess a unique pathogenicity mechanism that does not categorically fit into this classification scheme.

In keeping with the concept of gene-for-gene resistance, virulence factors produced by A. flavus during the colonization of maize tissues as well as maize kernel avirulence proteins have been the focus of multiple studies. These efforts have helped to better characterize the nature of this plant-pathogen interaction, and have sought to identify pathogen and host-derived proteins encoded by potential single-gene sources of host resistance or susceptibility. Proteomics-based techniques have identified several virulence proteins produced by $A$. flavus, most of which being hydrolytic enzymes. Examples of these enzymes are amylases, cellulases, chitinases, cutinases (e.g., phyto-cutinase), lipases, pectinases $(\mathrm{P} 2 \mathrm{c})$, proteases such as alkaline protease, and xylanases (Cleveland and Cotty, 1991; Guo et al., 1995; Chen et al., 1998, 1999; Fakhoury and Woloshuk, 1999; Mellon et al., 2000; Brown et al., 2001; Cleveland et al., 2004; Chen et al., 2009a; Pechanova et al., 2013). These enzymes are consistent with the biology and classification of $A$. flavus as a saprophyte since they typically catabolize decaying plant materials as a source of nutrition.

Several constitutively expressed and inducible proteins have been described in the literature, which have been shown to counter the function of other hydrolytic virulence proteins produced by $A$. flavus. For example, Chen et al. (1998) described a 14-kDa trypsin inhibitor (TI) which functions as an inhibitor of $\alpha$-amylase, a protein utilized by A. flavus for the catabolism of complex carbohydrates. The same group also showed that silencing the expression of the TI gene in maize increases the susceptibility of maize kernel tissue to A. flavus infection and aflatoxin contamination (Chen et al., 2009b). In addition, $\beta$-1,3-glucanases, chitinases, pathogenesis-related proteins 10 and 10.1 , ribosome inactivating proteins (RIPs), and zeamatin have also been shown to be involved in the resistance of maize against A. flavus (Mauch et al., 1988; Walsh etal., 1991; Huynh etal., 1992; Guo etal., 1997; Lozovaya et al., 1998; Chen etal., 2006; Chen et al., 2010; Xie et al., 2010). In peanut (Arachis hypogaea), Liang et al. (2005) reported that the increase of $\beta$-1,3-glucanases among resistant lines was higher than in the susceptible lines after infection with A. flavus.

Accumulation of such antifungal and avirulence proteins has been shown to contribute to the resistance observed in several maize lines along with morphological characteristics of resistant kernels such as thickened wax cuticles (Guo et al., 1995). Various breeding techniques have been employed to develop varieties with enhanced resistance to A. flavus and aflatoxin contamination on the basis of utilizing phenotypic screenings and molecular markers associated with known avirulence genes to identify quantitative trait loci (QTL) for selection (Brown et al., 2013). These efforts have met with some success such as in the case of Willcox et al. (2013) who identified 20 QTL explaining 22-43\% of phenotypic variation within a $\mathrm{F}_{2}$ mapping population derived from Mp313E $\times$ Va35. This study, along with others (Paul et al., 2003; Brooks et al., 2005; Kelley et al., 2012), illustrate two important challenges in breeding resistant maize varieties, including: (1) that resistance to A. flavus is a quantitative trait involving multiple genes rather than single-gene forms of gene-for-gene resistance, and (2) a large genotype $\mathrm{x}$ environment $(\mathrm{G} \times \mathrm{E})$ interaction conditions the expression of this trait. For example Willcox etal. (2013) determined that only 11 of the 20 identified QTL were consistently expressed across different environments with these accounting for $2.4-9.5 \%$ of phenotypic variance.

Environmental factors can have a significant effect on maize resistance to A. flavus and aflatoxin production, particularly abiotic stresses such as drought and heat stress. This was clearly demonstrated as early as 1977 when widespread and intense drought conditions in the Midwestern and Southeastern United States resulted in a high degree of aflatoxin contamination of maize kernels pre-harvest (Zuber and Lillehoj, 1979; Diener et al., 1987). However, maize genotypes possessing drought tolerance, such as Lo964 and Tex6, tend to be less susceptible to aflatoxin contamination (Guo et al., 2008; Luo et al., 2008; Jiang et al., 2012).

\section{RELATIONSHIP OF DROUGHT TOLERANCE, AFLATOXIN CONTAMINATION AND A. flavus RESISTANCE}

It has been hypothesized that there is an underlying relationship among various molecular mechanisms of drought stress adaptation and resistance to $A$. flavus infection and subsequent aflatoxin contamination. This connection has been demonstrated experimentally in a number of studies. Chen et al. (2007) found a number of drought stress-related proteins that were induced in response to A. flavus colonization in maize endosperm tissue including late embryogenesis abundant proteins LEA 3, 
14, peroxiredoxin (PER1), and a 17.9-kDa heat shock protein (HSP17.9). Pechanova etal. (2011) found that these proteins along with several antioxidant proteins, such as ascorbate peroxidase and superoxide dismutase (SOP), were up-regulated in resistant maize rachis tissue earlier in development and formed the basis, when combined with increased expression of antifungal and pathogenesis-related proteins, for resistance to A. flavus colonization.

It has also been shown that global defense regulators have the potential to modulate maize resistance to drought stress, oxidative stress, and possibly A. flavus resistance. The WRKY transcription factors have been shown to regulate the responses of multiple plant species to both biotic and abiotic stresses (Rushton et al., 2010). The transcription factor $Z m W R K Y 33$ was recently shown to enhance abscisic acid (ABA) signaling and enhance osmotic stress tolerance in maize seedlings ( $\mathrm{Li}$ et al., 2013). ZmWRKY33 along with $Z m W R K Y 19$, whose homolog in Arabidopsis thaliana (AtWRKY53) is known to induce a response to oxidative stress and regulate the expression of antioxidant enzymes like catalase (Miao et al., 2004; Eulgem and Somssich, 2007; Miao etal., 2007; Rushton etal., 2010). These factors were found to be up-regulated earlier in resistant maize varieties in response to A. flavus inoculation in whole kernel tissues (Fountain et al., 2013).

\section{OXIDATIVE RESPONSES OF PLANTS TO HERBIVORY}

Oxidative responses of plants to feeding damage by both chewing and piercing-sucking insects and nematodes have been described in recent years. Walling (2000) and Kaloshian and Walling (2005) described the piercing-sucking hemipteran insect feeding on crop plants as resembling plant pathogen infections that they are often associated with chitosan (oligogalacturonides produced by pectinases) and reactive oxygen species (ROS)-activated wound or defense signaling pathways in host plants. Kessler and Baldwin (2002) reviewed the molecular mechanisms underlying plant responses to insect herbivory and how they differ from pathogen infections. They concluded that insect herbivores are physiologically independent from their host plants, whereas pathogens are physiologically dependent on their host plants for their growth and development. Oxidative enzyme-mediated wounding responses also play a critical role in understanding plant responses to insect herbivory, although the insect-specific elicitors frequently modify the responses of their host plants, and allow the host plants to optimize their defenses against a specific insect pest (Kessler and Baldwin, 2002). Das et al. (2008) studied the accumulation of ROS in cowpea-root-knot nematode interaction and confirmed that the induction of resistance is relatively late in this system. Typically, hypersensitive response is closely associated with an oxidative burst in infected tissue.

Bi and Felton (1995) reported that corn earworm (Helicoverpa zea Boddie), herbivory caused significant increases in lipid peroxidation and hydroxyl radical formation in the soybean leaves. The activities of several oxidative enzymes (i.e., lipoxygenases, peroxidase, diamine oxidase, ascorbate oxidase, and NADH oxidase I) were also increased following $H$. zea herbivory on soybean (Glycine $\max$ ) leaves. They concluded that oxidative responses in the soybean plants may have led to a decrease in herbivory and an increase in oxidative damage to the plant. Ni et al. (2000) described the salivary enzyme profiles of the leaf-chlorosis-eliciting Russian wheat aphid (Diuraphis noxia Mordvilko), and the non-leaf-chlorosiseliciting bird cherry-oat aphid (Rhopalosiphum padi L.), which differ in oxidative enzyme activities. While only peroxidase activity was detected in $R$. padi, catalase activity was only detected in D. noxia. The oxidative responses of four cereal plants (i.e., susceptible "Arapahoe" and resistant "Halt" wheat, susceptible "Morex" barley, and resistant "Border" oat) to the feeding of the two species of aphid differed (Ni et al., 2001a). The chlorosiseliciting $D$. noxia feeding caused a three-fold increase in peroxidase activity in the resistant Halt wheat, and nine-fold increase in the susceptible Morex barley 9 days after infestation when compared to the control leaves. In contrast, $R$. padi did not cause any changes in peroxidase activity in any of the cereal leaves. At the same time, $D$. noxia feeding did not elicit any change in either catalase or polyphenol oxidase activity in comparison with either the $R$. padi-infested or the control cereal leaves (Ni et al., 2001a). Furthermore, oxidative bleaching in leaf chlorosis elicited by $D$. noxia was not detected, but Mg-dechelatase activity was increased in the D. noxia-elicited chlorosis in wheat leaves (Ni et al., 2001b).

Zavala etal. (2013) also proposed a cellular mechanism to decipher the influence of elevated $\mathrm{CO}_{2}$ on insect herbivory. They highlighted that oxidative enzyme activities in the subcellular organelles, such as peroxisomes and chloroplasts, via the jasmonic signaling pathway are likely to be critical factors in dissecting the molecular mechanisms of plant defenses against both biotic and abiotic stresses. In general, the oxidative responses of plants to pathogen infection and insect herbivory under varying environmental conditions (e.g., drought and the elevated $\mathrm{CO}_{2}$ ) are critical for the management of pest outbreaks and the reduction of mycotoxin contamination in agricultural crops.

\section{THE ROLE OF OXIDATIVE STRESS IN AFLATOXIN BIOSYNTHESIS}

The presence of increased expression of antioxidant mechanisms in resistant maize tissues leads to the hypothesis that increased resistance to ROS-induced oxidative stress may correlate to resistance to $A$. flavus and aflatoxin contamination. Although this conclusion seems credible due to the high degree of correlative evidence present in the literature, the exact mechanism of how this phenomenon functions has yet to be elucidated completely. More recent studies into the biology of $A$. flavus and the mechanisms regulating the production of aflatoxin may illuminate this issue (Magbanua etal., 2007; Roze et al., 2013).

Aflatoxin biosynthesis is a complex process involving multiple gene products and regulatory mechanisms coded for by an approximately 70-kb cluster of 25 genes (Yu et al., 2004). This pathway is responsible for the biosynthesis of five major mycotoxins: sterigmatocystin, and aflatoxins $B_{1}, B_{2}, G_{1}$, and $G_{2}$ (Yu et al., 2004), and is the focus of intensive research into methods of negatively regulating its function. Although the structure and biochemical characteristics of aflatoxins have been known since the 1960s (Asao et al., 1965; Wogan, 1966), the specific purpose of their 
production by $A$. flavus or other aflatoxigenic fungi has remained a mystery. Prior research exploring the roles of oxidative stress in regulating aflatoxin biosynthesis as well as recent discoveries into the upstream regulation of major pathway regulatory factors have begun to elucidate the biological function of aflatoxins (Roze et al., 2013). It has been shown that aflatoxin production by A. flavus is higher in maize kernel tissues containing higher levels of lipids, such as embryo tissues (Earle et al., 1946; Fabbri et al., 1980; Brodhagen and Keller, 2006). The roles of lipids in regulating aflatoxin biosynthesis in Aspergillus spp. have been investigated, particularly oxylipins (Reviewed in Gao and Kolomiets, 2009). Earlier research by Fabbri et al. (1983) found that seeds of high-oil crops such as peanut support higher levels of aflatoxin production by A. parasiticus than seeds of graminaceous plants such as maize or wheat, which contain higher levels of starch. In addition, they found that culturing $A$. parasiticus amended with peroxidized lipids resulted in significantly elevated aflatoxin production with no significant effect on fungal biomass (Fabbri et al., 1983).

Lipid peroxidation is a byproduct of lipid metabolism in peroxisomes as well as the reaction of naturally produced free fatty acids with ROS (Reverberi et al., 2012). Therefore, it is possible that excessive peroxisome function in the fungal mycelia or oxidative stress may be a causative factor in the production of aflatoxin. In vitro, Jayashree and Subramanyam (2000) showed that toxigenic strains of $A$. parasiticus have increased oxygen requirements, which they postulate to be a potential source of ROS accumulation, in comparison to non-toxigenic strains. In addition, they showed that higher levels of glutathione and thiobarbituric acid-reactive substances (TBARS), as well as antioxidant enzyme activities, were present in toxigenic strains in comparison to non-toxigenic strains. This indicated that oxidative stress may be a pre-requisite for aflatoxin production (Jayashree and Subramanyam, 2000). Also, Reverberi et al. (2012) found that bezafibrate and transformation of the Cymbidium ringspot virus $\mathrm{P} 33$ gene into A. flavus induced peroxisome proliferation resulting in an increase in aflatoxin production both in vitro and when cultured on maize kernel tissues in addition to increased levels of antioxidant enzyme gene expression, lipid metabolism, oxylipin biosynthesis, and ROS accumulation in the A. flavus mycelia. Recent studies have also found that cAMP and G-protein-mediated quorum sensing signaling pathways based on oxylipin perception can play a vital role in growth regulation and aflatoxin production in $\mathrm{A}$. nidulans (Affeldt et al., 2012). Such G-protein mediated signaling has also been reported in other Aspergillus spp. including A. fumigatus (Grice et al., 2013). Therefore, it may be concluded that oxidative stress in A. flavus induced by ROS and/or oxylipins in the growth environment/medium will result in increased aflatoxin production from a biochemical perspective.

Recent studies have also shown that ROS can play a role in the transcriptional regulation of aflatoxin and sterigmatosystin biosynthesis pathway genes. Reverberi et al. (2008) found that a putative binding site for the ApyapA gene, which regulates oxidative stress tolerance and conidiogenesis, was present in the promoter of the regulatory gene aflR in A. parasiticus, and that silencing ApyapA results in an increase in aflatoxin biosynthesis. It has also been shown that the basic leucine zipper (bZIP) transcription factor AtfB regulates the aflatoxin biosynthesis genes fas-1, ver-1, and omtA as well as antioxidant genes encoding for catalase and SOP (Hong et al., 2013). They also found that the promoter regions associated with AtfB also contained cAMP-responsive elements implicating cAMP in the regulation of aflatoxin biosynthesis (Hong et al., 2013).

\section{POTENTIAL REACTIVE OXYGEN SPECIES-MEDIATED CROSSTALK BETWEEN MAIZE AND A. flavus}

Given the apparent role of oxidative stress in the promotion of aflatoxin biosynthesis, the hypothesis has been proposed that aflatoxin may function as a form of antioxidant protection to Aspergilli (Reverberi et al., 2010). This would provide an explanation to the long standing question, rather the mystery, as to the biological significance of aflatoxin, although the potential antioxidant mechanism of action of aflatoxin has yet to be fully elucidated. In addition, this explanation also provides for the potential role of ROS and oxylipins cross-kingdom communication between maize and A. flavus.

Cross-kingdom communication between plants and various fungi through the use of oxylipins has been previously documented (Eckardt, 2008; Christensen and Kolomiets, 2011). Specifically, the role of oxylipins has been clearly illustrated in the specific interaction between maize and A. flavus (Gao and Kolomiets, 2009). In a recent study, it was found that maize lipoxygenase-3 (LOX3) is required for resistance to A. flavus indicating that certain 9-oxylipins can play important roles in suppressing aflatoxin biosynthesis while other oxylipins may promote aflatoxin biosynthesis (Gao et al., 2009). The role of LOX-1 in resistance mechanisms against $A$. flavus, $A$. nidulans, and $A$. parasiticus has also been implied in soybean (Doehlert et al., 1993; Burow et al., 1997), although there are contradicting reports on the subject in the literature. Mellon and Cotty (2002) found that soybeans lacking LOX activity were just as resistant to A. flavus and aflatoxin contamination as those possessing LOX activity. This seems to imply some degree of specificity in the role of LOX enzymes or their products in resistance to certain Aspergillus species.

In addition to oxylipins, other host-derived compounds may influence oxidative stress including ROS and phytohormones. It was found that 2-chloroethyl phosphoric acid (CEPA), the metabolic precursor to ethylene, was capable of reducing the expression of aflR and aflD (two key genes in the aflatoxin biosynthetic pathway), reducing the accumulation of oxidative compounds, and regulating glutathione redox in A. flavus mycelia (Huang et al., 2009). Therefore, host-derived ethylene may result in the reduction of ROS accumulation in A. flavus mycelia and reduce aflatoxin biosynthesis. This hypothesis seems plausible since the expression of the maize Ethylene Responsive Factor 1 ( $Z m E R F 1)$, a key transcription factor involved in ethylene and JA signaling, was found to be higher in the immature kernel tissues of the resistant maize inbred TZAR101 (Menkir et al., 2008) in comparison to the susceptible maize inbred B73 following A. flavus inoculation (Fountain et al., 2013).

Previous research has shown that maize varieties resistant to A. flavus tend to accumulate antioxidant enzymes, such as peroxidase and SOP, and tend to be more resistant to drought and heat stress than varieties susceptible to A. flavus (Guo 
et al., 2008; Pechanova etal., 2011). Given the reported role of oxidative stress in Aspergillus spp. biology, it may be possible for host-derived antioxidant proteins, phytohormones, and oxylipins to negatively regulate the production of aflatoxin in infecting $A$. flavus by reducing the level of oxidative stress endured by both the host and the fungus, particularly during drought or heat stress. Such an interaction may explain several observed phenomena in the literature. For example, Guo etal. (1996, 1997) observed that the pre-incubation of maize kernels in high-humidity conditions for 3 days prior to inoculation with A. flavus results in a significant reduction in aflatoxin contamination in comparison with kernels inoculated without pre-incubation. Given the fact that ROS such as hydrogen peroxide accumulates to maximum quantities two days postimbibition (DPI) followed by increased catalase activity beginning at three DPI in maize kernels (Hite et al., 1999), a combination of host-derived resistance and antioxidant proteins and reduced ROS production at the time of inoculation may have contributed to the reduction in aflatoxin production (Guo et al., 1996).

\section{CONCLUSION}

Determining the role of oxidative stress in the regulation of aflatoxin biosynthesis as well as the role of host defenses against both A. flavus infection and mycotoxin biosynthesis are critical areas of research for the mitigation of aflatoxin contamination in maize. Maize resistance to A. flavus is a complex, quantitative trait which is the culmination of the interaction of numerous resistanceassociated proteins and antioxidant enzymes which have been the subject of more than 50 years of rigorous research. Solutions to the problem of aflatoxin contamination of crops, particularly maize, have been elusive given the high level of environmental influence on the interaction and the lack of stable resistance in maize germplasm across multiple environments. By better understanding the role of oxidative stress and its remediation by the host and the pathogen, additional tools will be made available to counter the threat aflatoxin poses to food safety and security and further enhance the knowledge of cross-kingdom interactions which may be applied to other mycotoxin producing pathogens in various agricultural commodities.

\section{ACKNOWLEDGMENTS}

This work is partially supported by the U.S. Department of Agriculture Agricultural Research Service (USDA-ARS), the Georgia Agricultural Commodity Commission for Corn, and AMCOE (Aflatoxin Mitigation Center of Excellence). Mention of trade names or commercial products in this publication is solely for the purpose of providing specific information and does not imply recommendation or endorsement by the USDA. The USDA is an equal opportunity provider and employer.

\section{REFERENCES}

Affeldt, K. J., Brodhagen, M., and Keller, N. P. (2012). Aspergillus oxylipin signaling and quorum sensing pathways depend on $\mathrm{G}$ protein-coupled receptors. Toxins 4, 695-717. doi: 10.3390/toxins4090695

Amaike, S., and Keller, N. P. (2011). Aspergillus flavus. Ann. Rev. Phytopathol. 49, 107-133. doi: 10.1146/annurev-phyto-072910-095221
Asao, T., Büchi, G., Abdel-Kader, M., Chang, S., Wick, E. L., and Wogan, G. (1965). The structures of aflatoxins B1 and G1. J. Am. Chem. Soc. 87, 882-886. doi: 10.1021/ja01082a031

Bennett, J. W., and Klich, M. A. (2003). Mycotoxins. Clin. Microbiol. Rev. 16, 497-516. doi: 10.1128/CMR.16.3.497-516.2003

Bi, J., and Felton, G. (1995). Foliar oxidative stress and insect herbivory: primary compounds, secondary metabolites, and reactive oxygen species as components of induced resistance. J. Chem. Ecol. 21, 1511-1530. doi: 10.1007/ BF02035149

Brodhagen, M., and Keller, N. P. (2006). Signalling pathways connecting mycotoxin production and sporulation. Mol. Plant Pathol. 7, 285-301. doi: 10.1111/j.13643703.2006.00338.x

Brooks, T. D., Williams, W. P., Windham, G. L., Willcox, M. C., and Abbas, H. K. (2005). Quantitative trait loci contributing resistance to aflatoxin accumulation in the maize inbred Mp313E. Crop Sci. 45, 171-174. doi: 10.2135/ cropsci2005.0171

Brown, R. L., Chen, Z. Y., Cleveland, T. E., Cotty, P. J., and Cary, J. W. (2001). Variation in in vitro alpha-amylase and protease activity is related to the virulence of Aspergillus flavus isolates. J. Food Protect. 64, 401-404.

Brown, R. L., Menkir, A., Chen, Z. Y., Bhatnagar, D., Yu, J., Yao, H., et al. (2013). Breeding aflatoxin resistant maize lines using recent advances in technologies a review. Food Addit. Contam. Part A Chem. Anal. Control Expo. Risk Assess. 30, 1382-1391. doi: 10.1080/19440049.2013.812808

Burow, G., Nesbitt, T., Dunlap, J., and Keller, N. (1997). Seed lipoxygenase products modulate Aspergillus mycotoxin biosynthesis. Mol. Plant Microbe Interact. 10, 380-387. doi: 10.1094/MPMI.1997.10.3.380

Chanda, A., Roze, L. V., Kang, S., Artymovich, K. A., Hicks, G. R., Raikhel, N. V., et al. (2009). A key role for vesicles in fungal secondary metabolism. Proc. Natl. Acad. Sci. U.S.A. 106, 19533-19538. doi: 10.1073/pnas.0907416106

Chen, Z. Y., Brown, R. L., Cary, J. W., Damann, K. E., and Cleveland, T. E. (2009a). Characterization of an Aspergillus flavus alkaline protease and its role in the infection of maize kernels. Toxin Rev. 28, 187-197. doi: 10.1080/15569540903089221

Chen, Z. Y., Brown, R. L., Guo, B. Z., Menkir, A., and Cleveland, T. E. (2009b). Identifying aflatoxin resistance-related proteins/genes through proteomics and RNAi gene silencing. Peanut Sci. 36, 35-41. doi: 10.3146/AT07-005.1

Chen, Z. Y., Brown, R. L., Damann, K. E., and Cleveland, T. E. (2007). Identification of maize kernel endosperm proteins associated with resistance to aflatoxin contamination by Aspergillus flavus. Phytopathology 97, 1094-1103. doi: 10.1094/PHYTO-97-9-1094

Chen, Z. Y., Brown, R. L., Damann, K. E., and Cleveland, T. E. (2010). PR10 expression in maize and its effect on host resistance against Aspergillus flavus infection and aflatoxin production. Mol. Plant Pathol. 11, 69-81. doi: 10.1111/j.1364-3703.2009.00574.x

Chen, Z. Y., Brown, R. L., Lax, A. R., Guo, B. Z., Cleveland, T. E., and Russin, J. S. (1998). Resistance to Aspergillus flavus in corn kernels is associated with a $14-\mathrm{kDa}$ protein. Phytopathology 88, 276-281. doi: 10.1094/PHYTO.1998.88.4.276

Chen, Z. Y., Brown, R. L., Rajasekaran, K., Damann, K. E., and Cleveland, T. E. (2006). Identification of a maize kernel pathogenesis-related protein and evidence for its involvement in resistance to Aspergillus flavus infection and aflatoxin production. Phytopathology 96, 87-95. doi: 10.1094/PHYTO-96-0087

Chen, Z. Y., Brown, R. L., Russin, J. S., Lax, A. R., and Cleveland, T. E. (1999). A corn trypsin inhibitor with antifungal act inhibits Aspergillus flavus alpha-amylase. Phytopathology 89, 902-907. doi: 10.1094/PHYTO.1999. 89.10 .902

Christensen, S. A., and Kolomiets, M. V. (2011). The lipid language of plant-fungal interactions. Fungal Genet. Biol. 48, 4-14. doi: 10.1016/j.fgb.2010.05.005

Cleveland, T. E., and Cotty, P. J. (1991). Invasiveness of Aspergillus flavus isolates in wounded cotton bolls is associated with production of a specific fungal polygalacturonase. Phytopathology 81, 155-158. doi: 10.1094/Phyto-81-155

Cleveland, T. E., Yu, J. J., Bhatnagar, D., Chen, Z. Y., Brown, R. L., Chang, P. K., et al. (2004). Progress in elucidating the molecular basis of the host plant - Aspergillus flavus interaction, a basis for devising strategies to reduce aflatoxin contamination in crops. Toxin Rev. 23, 345-380. doi: 10.1081/TXR-200027892

Das, S., DeMason, D. A., Ehlers, J. D., Close, T. J., and Roberts, P. A. (2008). Histological characterization of root-knot nematode resistance in cowpea and its relation to reactive oxygen species modulation. J. Exp. Bot. 59, 1305-1313. doi: 10.1093/jxb/ern036 
Diener, U. L., Asquith, R. L., and Dickens, J. W. (1983). Aflatoxin and Aspergillus flavus in corn. So. Coop. Ser. Bull. 279, 112 pp.

Diener, U. L., Cole, R. J., Sanders, T. H., Payne, G. A., Lee, L. S., and Klich, M. A. (1987). Epidemiology of aflatoxin formation by Aspergillus flavus. Annu. Rev. Phytopathol. 25, 249-270. doi: 10.1146/annurev.py.25.090187.001341

Doehlert, D. C., Wicklow, D. T., and Gardner, H. W. (1993). Evidence implicating the lipoxygenase pathway in providing resistance to soybeans against Aspergillus flavus. Phytopathology 83, 1473-1477. doi: 10.1094/Phyto-83-1473

Earle, F. R., Curtis, J. J., and Hubbard, J. E. (1946). Composition of the component parts of the corn kernel. Cereal Chem. 23, 504-511.

Eckardt, N. A. (2008). Oxylipin signaling in plant stress responses. Plant Cell 20, 495-497. doi: 10.1105/tpc.108.059485

Eulgem, T., and Somssich, I. E. (2007). Networks of WRKY transcription factors in defense signaling. Curr. Opin. Plant Biol. 10, 366-371. doi: 10.1016/j.pbi.2007.04.020

Fabbri, A., Fanelli, C., Panfili, G., Passi, S., and Fasella, P. (1983). Lipoperoxidation and aflatoxin biosynthesis by Aspergillus parasiticus and A. flavus. J. Gen. Microbiol. 129, 3447-3452. doi: 10.1099/00221287-129-11-3447

Fabbri, A., Fanelli, C., and Serafini, M. (1980). Aflatoxin production on cereals, oil seeds and some organic fractions extracted from sunflower. Rendiconti Accademia Nazionale delle Sciencze detta dei XL 98, 219-228.

Fakhoury, A. M., and Woloshuk, C. P. (1999). Amyl, the alphaamylase gene of Aspergillus flavus: involvement in aflatoxin biosynthesis in maize kernels. Phytopathology 89, 908-914. doi: 10.1094/PHYTO.1999. 89.10.908

Fountain, J. C., Raruang, Y., Luo, M., Brown, R. L., and Chen, Z. Y. (2013). Maize WRKY transcription factors and their potential roles in regulating defense gene expression during Aspergillus flavus infection. Phytopathology 103(Suppl. 1), S1.4

Gao, X., Brodhagen, M., Isakeit, T., Brown, S. H., Göbel, C., Betran, J., et al. (2009). Inactivation of the lipoxygenase ZmLOX3 increases susceptibility of maize to Aspergillus spp. Mol. Plant Microbe Interact. 22, 222-231. doi: 10.1094/MPMI22-2-0222

Gao, X., and Kolomiets, M. V. (2009). Host-derived lipids and oxylipins are crucial signals in modulating mycotoxin production by fungi. Toxin Rev. 28, 79-88. doi: $10.1080 / 15569540802420584$

Glazebrook, J. (2005). Contrasting mechanisms of defense against biotrophic and necrotrophic pathogens. Annu. Rev. Phytopathol. 43, 205-227. doi 10.1146/annurev.phyto.43.040204.135923

Grice, C., Bertuzzi, M., and Bignell, E. (2013). Receptor-mediated signaling in Aspergillus fumigatus. Front. Microbiol. 4:26. doi: 10.3389/fmicb.2013.00026

Guo, B. Z., Chen, Z. Y., Brown, R. L., Lax, A. R., Cleveland, T. E., Russin, J. S., etal. (1997). Germination induces accumulation of specific proteins and antifungal activities in corn kernels. Phytopathology 87, 1174-1178. doi: 10.1094/PHYTO.1997.87.11.1174

Guo, B. Z., Chen, Z. Y., Lee, R. D., and Scully, B. T. (2008). Drought stress and preharvest aflatoxin contamination in agricultural commodity: genetics, genomics and proteomics. J. Int. Plant Biol. 50, 1281-1291. doi: 10.1111/j.17447909.2008.00739.x

Guo, B. Z., Russin, J. S., Brown, R. L., Cleveland, T. E., and Widstrom, N. W. (1996). Resistance to aflatoxin contamination in corn as influenced by relative humidity and kernel germination. J. Food Protect. 59, 276-281.

Guo, B. Z., Russin, J. S., Cleveland, T. E., Brown, R. L., and Widstrom, N. W. (1995). Wax and cutin layers in maize kernels associated with resistance to aflatoxin production by Aspergillus flavus. J. Food Protect. 58, 296-300.

Hite, D. R., Auh, C., and Scandalios, J. G. (1999). Catalase activity and hydrogen peroxide levels are inversely correlated in maize scutella during seed germination. Redox Rep. 4, 1-2. doi: 10.1179/135100099101534710

Hong, S. Y., Roze, L. V., Wee, J., and Linz, J. E. (2013). Evidence that a transcription factor regulatory network coordinates oxidative stress response and secondary metabolism in Aspergilli. MicrobiologyOpen 2, 144-160. doi: 10.1002/mbo3.63

Horn, B. W., Moore, G. G., and Carbone, I. (2009a). Sexual reproduction in Aspergillus flavus. Mycologia 101, 423-429. doi: 10.3852/09-011

Horn, B. W., Ramirez-Prado, J. H., and Carbone, I. (2009b). The sexual state of Aspergillus parasiticus. Mycologia 101, 275-280. doi: 10.3852/08-205

Huang, J.-Q., Jiang, H.-F., Zhou, Y.-Q., Lei, Y., Wang, S.-Y., and Liao, B.-S. (2009). Ethylene inhibited aflatoxin biosynthesis is due to oxidative stress alleviation and related to glutathione redox state changes in Aspergillus flavus. Int. J. Food Microbiol. 130, 17-21. doi: 10.1016/j.ijfoodmicro.2008.12.027
Huynh, Q. K., Hironaka, C. M., Levine, E. B., Smith, C. E., Borgmeyer, J. R., and Shah, D. M. (1992). Antifungal proteins from plants - purification, molecular cloning, and antifungal properties of chitinases from maize seed. J. Biol.Chem. $267,6635-6640$.

Jayashree, T., and Subramanyam, C. (2000). Oxidative stress as a prerequisite for aflatoxin production by Aspergillus parasiticus. Free Rad. Biol. Med. 29, 981-985. doi: 10.1016/S0891-5849(00)00398-1

Jiang, T., Fountain, J. C., Davis, G., Kemerait, R., Scully, B. T., Lee, R. D., et al. (2012). Root morphology and gene expression analysis in response to drought stress in maize (Zea mays). Plant Mol. Biol. Rep. 30, 360-369. doi: 10.1007/s11105-011$0347-9$

Kaloshian, I., and Walling, L. L. (2005). Hemipterans as plant pathogens. Annu. Rev. Phytopathol. 43, 491-521. doi: 10.1146/annurev.phyto.43.040204. 135944

Keen, N. T. (1990). Gene-for-gene complementarity in plant-pathogen interactions. Annu. Rev. Genet. 24, 447-463. doi: 10.1146/annurev.ge.24.120190.002311

Kelley, R. Y., Williams, W. P., Mylroie, J. E., Boykin, D. L., Harper, J. W., Windham, G. L., et al. (2012). Identification of maize genes associated with host plant resistance or susceptibility to Aspergillus flavus infection and aflatoxin accumulation. PLoS ONE 7:e36892. doi: 10.1371/journal.pone.0036892

Kessler, A., and Baldwin, I. T. (2002). Plant responses to insect herbivory: the emerging molecular analysis. Annu. Rev. Plant Biol. 53, 299-328. doi: 10.1146/annurev.arplant.53.100301.135207

Li, H., Gao, Y., Xu, H., Dai, Y., Deng, D., and Chen, J. (2013). ZmWRKY33, a WRKY maize transcription factor conferring enhanced salt stress tolerances in Arabidopsis. Plant Growth Reg. 70, 207-216. doi: 10.1007/s10725-013-9792-9

Liang, X. Q., Holbrook, C. C., Lynch, R. E., and Guo, B. Z. (2005). $\beta$-1,3-glucanase activity in peanut seed (Arachis hypogaea) is induced by inoculation with Aspergillus flavus and copurifies with a conglutin-like protein. Phytopathology 95, 506-511. doi: 10.1094/PHYTO-95-0506

Lozovaya, V. V., Waranyuwat, A., and Widholm, J. M. (1998). $\beta$-1,3-glucanase and resistance to Aspergillus flavus infection in maize. Crop Sci. 38, 1255-1260. doi: 10.2135/cropsci1998.0011183X003800050024x

Luo, M., Liu, J., Lee, R., and Guo, B. Z. (2008). Characterization of gene expression profiles in developing kernels of maize (Zea mays) inbred Tex6. Plant Breed. 127, 569-578. doi: 10.1111/j.1439-0523.2008.01538.x

Magbanua, Z. V., De Moraes, C. M., Brooks, T. D., Williams, W. P., and Luthe, D. S. (2007). Is catalase activity one of the factors associated with maize resistance to Aspergillus flavus? Mol. Plant Microbe Interact. 20, 697-706. doi: 10.1094/MPMI20-6-0697

Mauch, F., Mauchmani, B., and Boller, T. (1988). Antifungal hydrolases in pea tissue: 2. Inhibition of fungal growth by combinations of chitinase and beta-1,3glucanase. Plant Physiol. 88, 936-942. doi: 10.1104/pp.88.3.936

Mellon, J., and Cotty, P. (2002). No effect of soybean lipoxygenase on aflatoxin production in Aspergillus flavus-inoculated seeds. J. Food Protect. 65, 1984-1987.

Mellon, J. E., Cotty, P. J., and Dowd, M. K. (2000). Influence of lipids with and without other cottonseed reserve materials on aflatoxin B1 production by Aspergillus flavus. J. Agric. Food Chem. 48, 3611-3615. doi: 10.1021/jf0000878

Menkir, A., Brown, R. L., Bandyopadhyay, R., and Cleveland, T. E. (2008). Registration of six tropical maize germplasm lines with resistance to aflatoxin contamination. J. Plant Reg. 2, 246-250. doi: 10.3198/jpr2008.01.0028crg

Miao, Y., Laun, T., Zimmermann, P., and Zentgraf, U. (2004). Targets of the WRKY53 transcription factor and its role during leaf senescence in Arabidopsis. Plant Mol. Biol. 55, 853-867. doi: 10.1007/s11103-004-2142-6

Miao, Y., Laun, T. M., Smykowski, A., and Zentgraf, U. (2007). Arabidopsis MEKK1 can take a short cut: it can directly interact with senescence-related WRKY53 transcription factor on the protein level and can bind to its promoter. Plant Mol. Biol. 65, 63-76. doi: 10.1007/s11103-007-9198-z

Mideros, S. X., Windham, G. L., Williams, W. P., and Nelson, R. J. (2009). Aspergillus flavus biomass in maize estimated by quantitative real-time polymerase chain reaction is strongly correlated with aflatoxin concentration. Plant Dis. 93, 11631170. doi: 10.1094/PDIS-93-11-1163

Ni, X., Quisenberry, S. S., Heng-Moss, T., Markwell, J., Sarath, G., Klucas, R., et al. (2001a). Oxidative responses of resistant and susceptible cereal leaves to symptomatic and nonsymptomatic cereal aphid (Hemiptera: Aphididae) feeding. J. Econ. Entomol. 94, 743-751. doi: 10.1603/0022-0493-94.3.743

Ni, X., Quisenberry, S. S., Markwell, J., Heng-Moss, T., Higley, L., Baxendale, F., et al. (2001b). In vitro enzymatic chlorophyll catabolism in wheat elicited by 
cereal aphid feeding. Entomol. Exp. Appl. 101, 159-166. doi: 10.1046/j.15707458.2001.00900.x

Ni, X., Quisenberry, S. S., Pornkulwat, S., Figarola, J. L., Skoda, S. R., and Foster, J. E. (2000). Hydrolase and oxido-reductase activities in Diuraphis noxia and Rhopalosiphum padi (Hemiptera: Aphididae). Ann. Entomol. Soc. Am. 93, 595601. doi: 10.1603/0013-8746(2000)093[0595:HAORAI]2.0.CO;2

Paul, C., Naidoo, G., Forbes, A., Mikkilineni, V., White, D., and Rocheford, T. (2003). Quantitative trait loci for low aflatoxin production in two related maize populations. Theor. Appl. Genet. 107, 263-270. doi: 10.1007/s00122 -003-1241-0

Pechanova, O., Pechan, T., Rodriguez, J. M., Williams, W. P., and Brown, A. E. (2013). A two-dimensional proteome map of the aflatoxigenic fungus Aspergillus flavus. Proteomics 13, 1513-1518. doi: 10.1002/pmic.201100659

Pechanova, O., Pechan, T., Williams, W. P., and Luthe, D. S. (2011). Proteomic analysis of the maize rachis: potential roles of constitutive and induced proteins in resistance to Aspergillus flavus infection and aflatoxin accumulation. Proteomics 11, 114-127. doi: 10.1002/pmic.201000368

Reverberi, M., Punelli, M., Smith, C. A., Zjalic, S., Scarpari, M., Scala, V., et al (2012). How peroxisomes affect aflatoxin biosynthesis in Aspergillus flavus. PLoS ONE 7:e48097. doi: 10.1371/journal.pone.0048097

Reverberi, M., Ricelli, A., Zjalic, S., Fabbri, A. A., and Fanelli, C. (2010). Natural functions of mycotoxins and control of their biosynthesis in fungi. Appl. Microbiol. Biotech. 87, 899-911. doi: 10.1007/s00253-010-2657-5

Reverberi, M., Zjalic, S., Ricelli, A., Punelli, F., Camera, E., Fabbri, C., et al. (2008). Modulation of antioxidant defense in Aspergillus parasiticus is involved in aflatoxin biosynthesis: a role for the ApyapA gene. Eukaryot. Cell 7, 988-1000. doi: 10.1128/EC.00228-07

Roze, L. V., Hong, S.-Y., and Linz, J. E. (2013). Aflatoxin biosynthesis: current frontiers. Annu. Rev. Food Sci. Tech. 4, 293-311. doi: 10.1146/annurev-food083012-123702

Rushton, P. J., Somssich, I. E., Ringler, P., and Shen, Q. J. (2010). WRKY transcription factors. Trends Plant Sci. 15, 247-258. doi: 10.1016/j.tplants.2010.02.006

Shephard, G. S. (2008). Impact of mycotoxins on human health in developing countries. Food Addit. Contam. Part A Chem. Anal. Control. Expo. Risk Assess. 25 146-151. doi: 10.1080/02652030701567442

Smart, M. G., Wicklow, D. T., and Caldwell, R. W. (1990). Pathogenesis in Aspergillus ear rot of maize - light microscopy of fungal spread from wounds. Phytopathology 80, 1287-1294. doi: 10.1094/Phyto-80-1287

Trenk, H. L., and Hartman, P. A. (1970). Effects of moisture content and temperature on aflatoxin production in corn. Appl. Microbiol. 19, 781-784.

Walling, L. L. (2000). The myriad plant responses to herbivores. J. Plant Growth Reg. 19, 195-216. doi: 10.1007/s003440000026
Walsh, T. A., Morgan, A. E., and Hey, T. D. (1991). Characterization and molecular cloning of a proenzyme form of a ribosome-inactivating protein from maize: novel mechanism of proenzyme activation by proteolytic removal of a 2.8 kilodalton internal peptide segment. J. Biol. Chem. 266, 23422-23427.

Willcox, M. C., Davis, G. L., Warburton, M. L., Windham, G. L., Abbas, H. K., Betrán, J., et al. (2013). Confirming quantitative trait loci for aflatoxin resistance from Mp313E in different genetic backgrounds. Mol. Breed. 32, 15-26. doi: 10.1007/s11032-012-9821-9

Wogan, G. N. (1966). Chemical nature and biological effects of the aflatoxins. Bacteriol. Rev. 30, 460.

Xie, Y.-R., Chen, Z. Y., Brown, R. L., and Bhatnagar, D. (2010). Expression and functional characterization of two pathogenesis-related protein 10 genes from Zea mays. J. Plant Physiol. 167, 121-130. doi: 10.1016/j.jplph.2009. 07.004

Yu, J., Chang, P.-K., Ehrlich, K. C., Cary, J. W., Bhatnagar, D., Cleveland, T. E., etal. (2004). Clustered pathway genes in aflatoxin biosynthesis. Appl. Environ. Microbiol. 70, 1253-1262. doi: 10.1128/AEM.70.3. 1253-1262.2004

Zavala, J. A., Nabity, P. D., and Delucia, E. H. (2013). An emerging understanding of mechanisms governing insect herbivory under elevated CO2. Annu. Rev. Entomol. 58, 79-97. doi: 10.1146/annurev-ento-120811-153544

Zuber, M., and Lillehoj, E. (1979). Status of the aflatoxin problem in corn. J. Environ. Qual. 8, 1-5. doi: 10.2134/jeq1979.00472425000800010001x

Conflict of Interest Statement: The authors declare that the research was conducted in the absence of any commercial or financial relationships that could be construed as a potential conflict of interest.

Received: 26 November 2013; accepted: 21 January 2014; published online: 05 February 2014.

Citation: Fountain JC, Scully BT, Ni X, Kemerait RC, Lee RD, Chen Z-Y and Guo B (2014) Environmental influences on maize-Aspergillus flavus interactions and aflatoxin production. Front. Microbiol. 5:40. doi: 10.3389/fmicb.2014.00040

This article was submitted to Food Microbiology, a section of the journal Frontiers in Microbiology.

Copyright (c) 2014 Fountain, Scully, Ni, Kemerait, Lee, Chen and Guo. This is an openaccess article distributed under the terms of the Creative Commons Attribution License (CC BY). The use, distribution or reproduction in other forums is permitted, provided the original author(s) or licensor are credited and that the original publication in this journal is cited, in accordance with accepted academic practice. No use, distribution or reproduction is permitted which does not comply with these terms. 